\title{
Global Climate Change and Suffering of Woman; A Case of Bangladesh
}

\author{
Mohammed Shahjalal* \\ Department of Law, East West University, Dhaka, Bangladesh \\ *Correspondence: shahjalal @ewubd.edu (Mohammed Shahjalal, Senior Lecturer, Department of Law, East West University, \\ Dhaka, Bangladesh).
}

\begin{abstract}
Bangladesh, a South Asian country, is critical because of its vulnerability to climate-sensitive diseases, reliance on climate-sensitive livelihoods, anticipated crop losses, and high rates of poverty and malnutrition. Women are disproportionately affected by climate change, and it has a disproportionate effect on them across a range of extreme events. The goal of this project is to gain a better understanding of climate change, its effects, and the climate resilience of women in South Asia. Additionally, it discusses discrepancies and proposes future policy recommendations. Climate change is increasingly recognized as a cause for concern, and the current review is appropriate given the devastating effects of climate change on South Asian countries.
\end{abstract}

Keywords: Climate change, Environmental disaster, Flood, Gender, Women's right, and Developed countries.

\section{INTRODUCTION:}

The climatic condition of the world has been changing with time due to increasing temperature. Global climate change not only influenced the environment, also driving profound social and economic impacts worldwide. The rapid industrialisation of developed countries makes a significant contribution to temperature rise and related climate change. Although developing countries contribute less to temperature rise through industrialization, they are the ultimate sufferers. People of some developing countries, who have less capacity to adjust with environmental change, have been suffering from consequences of climatic disasters, climate change and related disasters like flooding, storm surges and drought make the country's condition worse. Bangladesh is a small developing country like that where serious consequence has been created due to climate change. Geographically Bangladesh is one of the most vulnerable developing country due to climate change. Bangladesh's southern territory (coastal region) is next to the Bay of Bengal, and the coastline plains are only two metres above sea level.

UniversePG I www.universepg.com

\section{Literature Review}

In many developing and least developed countries (LDC), women are treated inequitable to men in different aspects. For example, in developing countries, women are less involved in the job sector. There are some causes of women's less involvement in the job sector. And often, including especially in Bangladesh, when women do participate in cash economy, they are located in precarious and poorly paid work (Perrons, 2015) and the change in climate has wideranging social, economic, and political implications (Bennett, 2005). In other words, recognizing the differences between men and women motivates people to identify their specific roles in their family, community, and country. Another key difference between the poor and the affluent is their varying degrees of access to information, resources, and networks. The evaluation measures the potential effect of an activity on men and men, as well as women, and gender relations (Hunt, 2004). It is important to keep in mind that Bangladesh is not the only former LDC member; for example, Nepal has a majority of its poor population being 
female, making them particularly vulnerable. Natural resources are critical to women's economic wellbeing. Due to cultural, social, policy, and legal systems, women are more likely to encounter obstacles when trying to gain access to resources such as land, clean water, and health care for their family. They are more affected by climate change, which raises their level of risk (Biswas et al., 2021; Leduc, 2009). The women in developing countries are getting fewer facilities to educate themselves. The girls are used as their mother's helping hand in household activities. In most of the families, household activities, child rearing and take care of the old people are the responsibilities of a women; like There is also a literature related to the triple burden of women's work - productive, reproductive and cash economy work. So, illiteracy among women or girls is higher compared to men or boys. That is why illiteracy is a great barrier for women to getting any job. Moreover, women cannot involve in the job for earning because the wages in most of the job sector are also very less for them. That is why selffinancial support to maintain a family as a single mother and live separately with their child is harder for a woman in developing countries like Bangladesh compared to other developed countries. As a result, dependency on husband for financial support is very common there. To answer the above question first, one needs to understand that there are some other issues related to each other. In Bangladesh, it is a provision to give women less inherited land from parents by inheritance (Ahmed et al., 2016). So, women have very fewer assets and money comparing to men for supporting their family. Women's fewer properties are also a reason behind the suffering of them. It was studied that, women who have some properties are less affected by domestic violence (Lentz, 2018). Some women are forced to live together after marriage, although they are suffering from domestic violence. Because on the one hand, few women have the financial capabilities to live separately and on the other hand socially or culturally that was not accepted in developing countries like Bangladesh (Nur et al., 2021). Moreover, social security of single mother is also very terrifying there. So, violation of human rights for women is very prominent in developing countries. Climate change has developed into a global security threat. It is a significant threat to long-term growth, UniversePG I www.universepg.com social justice, and respect for human rights. Climate change affects vary by region, generation, income level, and occupation, as well as between men and women. Women are more vulnerable to climate change than men. Climate change is the country's number one concern for the economy of Bangladesh. Bangladesh has a female population of about half of the overall population. They are more vulnerable than men due to their poverty, societal chores and responsibilities, and social system status (Islam, 2016; Tanny and Rahman, 2016).

By signing the 1992 Convention on Climate Change and the 2005 Kyoto Protocol, the government identified climate change as a top priority. The government has launched a variety of steps to prepare for the effects of Climate Change. Climate change is affecting the livelihoods and life of around 160 million people in the country (Nishat, 2016). According to Fatma Denton, (2002) critical development issues have been sidelined, if not outright ignored, from policy debates on climate change. It is critical that the repercussions of climate change do not further impoverish already marginalized parts of society. Olmos argues that the amount to which a natural or social system is vulnerable to climate change-related damage is a function of the severity of the change and the system's sensitivity to changes in temperature. This article argues that in order to ensure a sustainable future, climate change policy must include the interests of all stakeholders. The Global Environment Facility and the Kyoto Protocol's Clean Development Mechanism can both contribute to ensuring sustainable development. Additionally, Zayeda Sharmin indicated that women had fewer financial resources and decision-making authority than men to respond to climate-related challenges. The majority of climate change challenges, strategies, and projects do not take a gender-neutral approach. Recent natural disasters have disproportionately afflicted the poor. In poor countries such as Bangladesh, women living in poverty bear a disproportionate share of the consequences of climate change. Due to their lack of access to and control over natural resources, technologies, and credit, impoverished women have fewer resources available to them to cope with seasonal and episodic weather patterns and natural disasters. Climate change exa- 
cerbates resource scarcity and instability in some labor markets, resulting in more male migration and an increase in the number of women left behind to bear greater agricultural and household obligations. Nonetheless, climate change is now a reality in a large number of countries, as well as a tremendously tough and complex development challenge. Women and men have distinct needs, objectives, and options for mitigating and adapting to the effects of climate change. Climate change's impacts and consequences are not gender neutral and are likely to increase existing inequities between men and women. Women are disproportionately impacted by climate change as a result of their social positions, inequality, and poverty. Women must be included in these processes and tactics because they have more rights, are more vulnerable, and have a variety of viewpoints and experiences. In Bangladesh, women are disproportionately affected by climate change and calamities. Women are typically poorer than men, have less access to, ownership of, and control over resources, and have fewer prospects for livelihood. Women frequently lack access to education and information, leaving them without the necessary expertise to adapt to climate change. Numerous government measures are aimed at combating climate change at the moment, but many overlook gender inequities and vulnerabilities (EMPOWER, 2019).

Even the concerned ministry expressed its concern in National Action Plan (NAP). It was stressed that women's historical circumstances have resulted in their systematic exclusion from meaningful involvement in global economies. Greater gender equality can boost productivity, improve the next generation's development outcomes, and make institutions more representative. Over the previous three decades, over half a billion women have entered the global work force. By 2014 , women will control $\$ 15$ trillion in global expenditure and will account for almost two-thirds of all consumers spending globally by 2028. According to The Economist, women's employment growth in developed economies contributed more too global growth than China did in the last decade (Karim, 2020).

In comparison to the United States, women have increased their share of all jobs from $37 \%$ to UniversePG I www.universepg.com approximately $48 \%$ during the last 40 years. This equates to more than $\$ 3.5$ trillion - more than Germany's GDP and more than half of the GDPs of China and Japan (McKinsey, 2014).

\section{Rational of the Study}

Sea levels have been gradually rising as a result of global warming. As a result, Bangladeshis, particularly those residing in the country's coastal regions, face a substantial risk from climate change. Other than the climatic consequences, the country has different types of issues that make the situation worse. Such as the country has little national wealth, shortage of energy resources, big population compare to land area. As a result of climate change and related disasters, it creates dual pressure on human livelihoods. Although all the people suffer greatly due to those changes, women suffer disproportionately compared to men. Female victims are estimated to outnumber male victims after natural disasters (Alam and Rahman, 2014), hence women bear a greater burden of responsibility for the evacuation of family members during disasters; they do not receive the same benefits as males when confronted with a risky scenario (Denton, 2002). Gender inequality enhances the vulnerable situation which has been created due to climate change. This type of disparity indicates a clear lack of rightness among men and women. However, a comparative analysis of developed and developing countries regarding the issue of women rights exposed different findings. Women in developed countries get better rights (Ahmed et al., 2016). That is why, a question arises- whether to maintain human rights for all in the world. What should we change to maintain human rights in developing countries? Should we follow the developed countries? Should we change the culture of the developing countries? How it possible to maintain equity among developed and developing countries?

\section{Research Objectives:}

This research aims to analyse data on social and economic impacts in developing countries. Data on the percentage of vulnerable men and women in a particular region would collect to help in decision making. More attention will be placed on gathering data on gender-specific challenges. This could aid in determining how much misery has increased as a result of slow climate change. 


\section{METHODOLOGY:}

This paper attempts to explain the problem through a literature review and a conceptual structure approach. In order to recognize the vulnerability of women to climate change and its effects, the authors conducted both offline and online reviews for this report. Results The findings of this study indicate a strong correlation between climate change and the vulnerability of women in South Asia.

The proposed researches will con-duct interviews with men and women in the affected region. The research will also include literature research, data collection, data review, and interpretation of results and comparison of information. This research will mainly base on the issues of climate change and human rights of most affected climate victims. It wills also analyses climate justice perspectives to maintain human rights of the most affected climate victims. Much research has already been done about the issues of climate disasters and related consequences in developing countries. Nevertheless, no previous research has prioritized human rights issues. Moreover, a cross-country research about the issue has not been researched before. This study aims to evaluate prospective and sustainable solutions to manage human rights of most affected climate victims. As a result, despite significant hurdles, all three places considered for this research have achieved progress in terms of mainstreaming and implementing DRR and adaptation. A whole-of-government strategy is required for adaptation to be mainstreamed and the gap between planning and execution to be bridged. Credible, capable institutions committed to gathering objective, relevant, and easily accessible data are essential. Addressing the implementation gap requires the availability of money from both domestic and international sources.

\section{Developing and Developed Countries}

The researches on human rights in developing and developed countries have shown different findings (Cornwall et al., 2004). Some cultural differences between developed and developing countries are very prominent, which are related to some issues of human rights. It was studied that, in developed countries, comparatively more women are involved in jobs and have the self-financial support of their own. If they want to live as a single mother with their child, it is economically viable and also accepted socially there.

\section{Social Rights; Proportinate or not?}

Those issues make women of developing countries more vulnerable compared to men. We know from different research articles that women suffer dis-proportionately (Arora and Jonsson, 2011; Parkinson, 2011). That is why assisting women is a main issue. If the majority of women and girls-related social and disaster issues can be resolved, it is reasonable to believe that we will achieve better success in defending human rights. Women are an integral element of our society, and hence the success rate of a society cannot be calculated without them. Climate change and related calamities exacerbate difficulties with women's social rights. During Bangladesh's 1991 cyclone, many women were kept at home with their children while they awaited their husband's evacuation decision (World Health Organisation, 2005). Climate disasters put women's lives at risk because they lack the ability to make their own choices. Honduras is an exceptional example of this, having managed the 1998 Hurricane with zero fatalities due to a gender-sensitive approach to disaster management (Aguilar, 2009). This example explains how a gender-based approach to vulnerability might be employed. Climate change and gender equality have a negative link, according to study (Hossain et al., 2021). Domestic violence, including rape, has increased as a result of climate change (Eastin, 2018).

Typically, men and women seek refuge under the same roof during calamities. Domestic violence rose as a result. Occasionally, women are murdered following a rape, but the rapist is never brought to justice. If that woman is still living, she will face social rejection if she marries. This has become a growing concern in Bangladesh in recent years. This is a widespread problem in developing countries, but is not prevalent in developed countries. According to United Nations Human Development Report, (2020) the rich western nations were arguing basically for civil and political rights, while the socialist countries and some developing countries, and were demanding more social and economic rights. So, developed countries might be unaware of those issues of human rights prevailing in developing countries. In developing countries other 
than human rights and social security there are some other major issues like poverty, hunger, malnutrition, illiteracy, which are the main barriers to overcome the issue of human rights or women rights. The Government of the country can not manage all pressures that have been coming from different sectors. As the country has limited national wealth, it is not possible to maintain cost of redevelopment a road or house destroyed due to disaster and lacking of food shortage which is already exist in the country. However, in developed countries basic need of food, shelter and clothes had been gained. So that they can manage climatic effects and better human rights for all compared to developing countries. Developed countries have been attaining the benefits of industrialisation; so they have some responsibilities to fulfil the rights of most affected victims of climate change. Responsibility depends on vulnerable position, suffering, economical stability, and contribution to pollution or some other circumstances. With other efforts like new planning, development, labour and cost, finance is a most important factor among those. Climate finance to tackle the disaster effects is very important. Financing the poor developing countries is a responsibility and a part of humanity for developed countries. The Intergovernmental Panel on Climate Change (IPCCC), and alongside international civil society organizations, is now focusing on adaptation, mitigation and more recently loss and damages. It would be worthwhile acknowledging these different frameworks for responding to climate change, especially for developing countries. But some injustice generates over poor developing countries. Promises from Conference of the Parties 15 and 16 about fund flow and climate finance balance do not work properly (United Nations Framework Convention on Climate Change, 2011). Their promises just signed in the written paper but the action is different in real life. For example, USA signed the paper of agreement to protect the environment from pollution, but they bought sugarcane from Brazil to make fuel which pollutes the environment (Archer and Szklo, 2016). Although USA finance to mitigating the pollution but they continuously make pollution and enhancing climate change. They concern about profit from fuel production but not about climate change and related sufferings of poor developing countries. Moreover, in UniversePG I www.universepg.com recent time developed countries try to minimise the financial commitment (Pickering et al., 2015). There are some other issues related to such type of decision of developed countries. For example, in recent years China and India are two major contributors to emission. These countries economically developed recently through industrialisation. Their $\mathrm{CO}_{2}$ emission record surpassed the record of the USA, the biggest emitter. Emission by India is similar to Japan or Russia. Consequently, $\mathrm{CO}_{2}$ emission in Asia will be reaching $190 \%$ of the 2010 level by 2030 (Kameyama et al., 2016). However, their financial contribution in emission control is not satisfactory. So developed countries now refuse to take all financial responsibility because some developing countries now have capabilities to mitigate the financing issues. Some other issues like disparity in the share of funds arise because justice and equity debates do not focus on vulnerable communities (Barret, 2013). The poor people who have less adaptive capacity are in vulnerable position. Due to unavailability of good quality data and implementation capacity, proper plan can not take for most vulnerable communities (Dutta, 2015). It is a matter of humanity to help them depending on their vulnerable position.

\section{Future Research Suggestions}

Women must be at the forefront of climate change adaptation research, policy, and action. Women lack land rights, ownership of means of production, technology, financing, information, and training linked to climate adaptation, according to the study. Due to their knowledge, many duties, and involvement in productive regions, women are critical for establishing sustainable adaption solutions. Increased decisionmaking authority for women at the family and community level on agricultural cultivation can result in increased agricultural production, providing food security, and eventually, revenue. Women are already responding to the effects of climate change in numerous sectors and are acutely aware of their own and family requirements.

\section{CONCLUSION:}

Climate change has a significant socioeconomic impact on women in South Asia, particularly in agriculture, livelihoods, food security, physical and mental health, and water and sanitation. Consequences in 
practise additionally, the paper emphasizes the importance of gender-sensitive climate change mitigation programmes in order to avoid climate change impeding regional development and poverty reduction. Consequences on a social level. The outcomes of this research will aid families in escaping poverty by using adaptive strategies with proactive assistance from the government and grassroots organisations. Additionally, the new study calls for governments to embrace more gender- and climate-sensitive policies, as well as intervention- and evidence-based research in South Asian countries.

\section{ACKNOWLEDGEMENT:}

Author wishes to thanks who participated in this study by sharing their knowledge and time to make this research successful.

\section{CONFLICTS OF INTEREST:}

The author declares there are conflicts of the interest with respect to the research, and publication of this article.

\section{REFERENCES:}

1) Ahmed, A., Lawson, E., Mensah, A., Gordon, C. and Padgham, J. (2016). Adaptation to climate change or non-climatic stressors in semi-arid regions? Environ. Development, 20, pp.45-56.

2) Alston, M. (2017). Women and Climate Change in Bangladesh. $1^{\text {st }}$ edition, ASAA Women in Asia Series.

https://www.amazon.com/Women-Climate-Chan ge-Bangladesh-ASAA/dp/1138026042

3) Archer, M. and Szklo, A., (2016). Can increasing gasoline supply in the United States affect ethanol production in Brazil? Renewable Energy, 95, pp.586-596.

4) Bangladesh Climate Change and Gender Action Plan, (2013). (No. 978-984-33-7730-2). November 14. Ministry of Environment and Forest Government of the People's Republic of Bangladesh. http://nda.erd.gov.bd/en

5) Biswas A, Rahman MS, Yeasmin S, Sikder MKU. (2021). Assessment of radiation risk on healthcare workers and public in \& around two largest hospital campuses of Bangladesh, Eur. J. Med. Health Sci., 3(3), 48-57. https://doi.org/10.34104/ejmhs.021.048057
6) Cornwall, Andrea, and Celestine NyamuMusembi, (2004). "Putting the 'Rights-Based Approach' to Development into Perspective." Third World Quarterly, 25(8), pp. 1415-1437. www.jstor.org/stable/3993794

7) Denton, Fatma, (2021). "Climate Change Vulnerability, Impacts, and Adaptation: Why Does Gender Matter?" Gender and Development, 10(2), pp. 10-20. www.jstor.org/stable/4030569

8) Dewan, Camelia, (2020). 'Climate Change as a Spice': Brokering Environmental Knowledge in Bangladesh's Development Industry." Ethnos, 03(1), pp. 1.

https://doi.org/10.1080/00141844.2020.1788109

9) Eastin, Joshua, (2018). "Climate Change and Gender Equality in Developing States." World Development, 107(1), pp. 289-305, www.sciencedirect.com/science/article/pii/S03057 50X1830066410.1016/j.worlddev.2018.02.021

10) Gebremedhin, Teklu, (2020). "Factors That Affect Female Trainees' Academic Achievement in Teacher Training Colleges of Tigrai, Ethiopia." J. of Educat. and Practice, 11(1), p. 1. www.iiste.org/Journals/index.php/JEP/article/view/ $\underline{51223}$

11) Golam, Kibria, (2018). "Climate Change Impacts on Women in the LDC \& Developing Countries." 46(5).

https://doi.org/10.13140/RG.2.2.11876.01921/1

12) Hossain MR, Islam MA, and Hasan M. (2021). Assessment of medical waste management practices: a case study in Gopalganj Sadar, Bangladesh. Eur. J. Med. Health Sci., 3(3), 6271. https://doi.org/10.34104/ejmhs.021.062071

13) Kameyama, Yasuko et al. (2021). "Finance for Achieving Low-Carbon Development in Asia" $J$. of Cleaner Production, 128(4), pp. 201-20 www.jstor.org/stable/10.1016/j.jclepro.2014.12.089

14) Karim et al. (2019). "Legal Activism for Ensuring Environmental Justice." Asian J. of Com. Law, 7(1). https://doi.org/10.1515/1932-0205.1344

15) Lentz, Erin C (2021). "Complicating Narratives of Women's Food and Nutrition Insecurity: Domestic Violence in Rural Bangladesh." World Development, 104, pp. 271-280. www.jstor.org/stable/10.1016/j.worlddev.2017.11. $\underline{019}$ 
16) "Mary Robinson Foundation, (2015). Climate Justice. www.mrfcj.org/

17) Nabi, S, and A J. (2019). "Global Climate Strike: Dhaka Students Decry Climate Change.” Dhaka Tribune, 20 Sept., 2019.

www.dhakatribune.com/climate-change/2019/09/ 20/global-climate-strike-dhaka-students-decry-cli mate-change

18) Naz, Farha et al. (2020). "Adaptation Strategies to Floods: A Gender-Based Analysis of the Farming-Dependent Char Community in the Padma Floodplain, Bangladesh." International J. of Disaster Risk Reduction, 28(9), pp. 519-530, www.jstor.org/stable/10.1016/j.ijdrr.2017.12.016

19) Nations, United, (2021). "United Nations Framework Convention on Climate Change, (No. 16)." Unfccc.int, 2021.

20) Nur MNB, Rahim MA, and Rasheduzzaman M. (2021). Identifying cyclone shelter facilities and limitations for enhancing community resiliency in coastal areas of Bangladesh, Asian J. Soc. Sci. Leg. Stud., 3(4), 107-118.

https://doi.org/10.34104/ajssls.021.01070118

21) Rahman, A. (2020). “Climate Justice.” New Age | the Most Popular Outspoken English Daily in Bangladesh, 10 Sept., www.newagebd.net/article/113092/climate-justice

Accessed 7 Aug. 2021.

22) Reggers, Amy, (2019). "Climate Change Is Not Gender Neutral: Gender Inequality, Rights and Vulnerabilities in Bangladesh." Confronting Climate Change in Bangladesh, pp. 103-118, https://doi.org/10.1007/978-3-030-05237-9_8

23) Reliefweb, (2021). "Bangladesh Demands Climate Justice - Bangladesh.” Relief Web. 2011. https://reliefweb.int/report/bangladesh/bangladeshdemands-climate-justice

24) Shaila Shahid, M., \& Saleemul Huq, D. (2019). International Centre for Climate Change and Development, Women and Girls are the "Back- bone" of Building Climate Resilience. International Centre for Climate Change and Development.

http://genderandenvironment.org/resource/banglad esh-climate-change-gender-action-plan-ccgapreport/

25) "Staying on Track: Tackling Corruption Risks in Climate Change | United Nations Development Programme (2021)." UNDP. www.undp.org

26) Salim Momtaz, and Muhammad Asaduzzaman, (2019). Climate Change Impacts and Women's Livelihood: Vulnerability in Developing Countries. Abingdon, Oxon; New York, Routledge.

27) Tanjeela, Mumita, and Shannon Rutherford, (2020). "The Influence of Gender Relations on Women's Involvement and Experience in Climate Change Adaptation Programs in Bangladesh." SAGE Open, 8(4).

https://doi.org/10.1177/2158244018812620

28) The Financial Express, (2021). "Empowerment of Rural Women for Tackling Climate Change." The Financial Express, 22 July 2021.

https://thefinancialexpress.com.bd/views/empower ment-of-rural-women-for-tackling-climate-change1599746962

29) UNESCO, (2020). "Climate Change and Gender Equality | United Nations Educational, Scientific and Cultural Organization." 17 Nov., 2020.

www.unesco.org

30) UNWOMEN, (2015). Women in Bangladesh build resilience against climate change.

https://www.unwomen.org/en/news/stories/2015/9/ bangladesh-climate-change

31) WHO, (2019). Gender and Health in Disasters." www.who.int/gender-equity-rights/knowledge/a8 5575/en/

32) "Women's Empowerment Is Vital for Climate Resilience - but the Burden of Survival in Bangladesh Should Not Rest on Their Shoulders Alone." Dhaka Tribune, 9 Feb. 2020.

Citation: Shahjalal M. (2021). Global climate change and suffering of woman; a case of Bangladesh, Asian J. Soc. Sci. Leg. Stud., 3(4), 158-164. https://doi.org/10.34104/ajssls.021.01580164 @) (9) 